\title{
Quais os livros de Química que foram, ou são, mais importantes para mim?
}

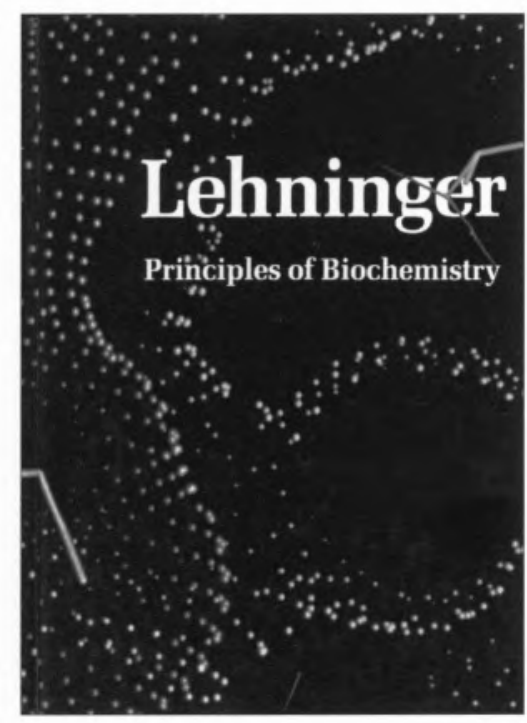

"Lehninger - Principles of Biochemistry" de Albert L. Lehninger, 1982, Worth Publishers, Inc.

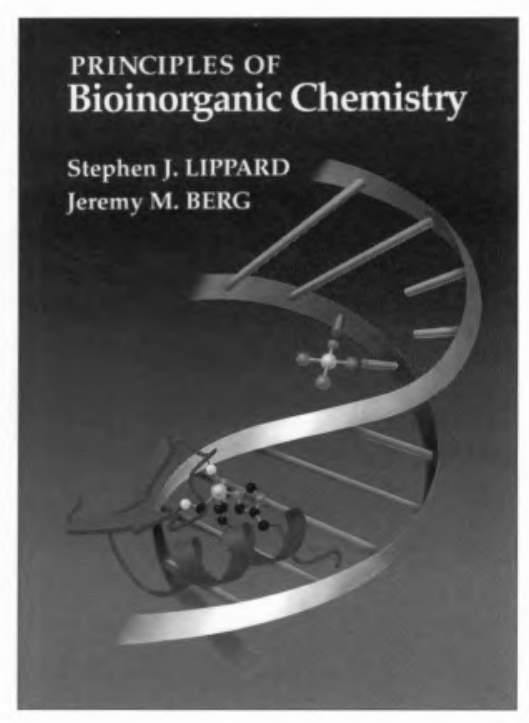

"Principles of Bioinorganic Chemistry" de Stephen J. Lippard e Jeremy M. Berg, 1994, University Science Books.
"Quais os livros de Química que foram, ou são, mais importantes para mim? Tarefa ingrata, pois muitos foram os livros utilizados ao longo dos últimos anos e dos quais guardo boas recordaçōes. Logo, a resposta (necessariamente sintética) será dada em termos dos que me ajudaram a tomar uma decisão no meu percurso como químico.

Livro primeiro:

"Química" de Victor M.S. Gil e A. Correia Cardoso, 3. a edição, 1982, Livraria Almedina Editora, Coimbra.

Aquilo que considero como os meus primeiros livros de Química (obrigatórios para a frequência do meu $12 .^{\circ}$ ano) e que me fascinaram pela facilidade de leitura. Levaram-me a procurar avidamente mais leitura de Química na biblioteca da minha escola secundária (E. S. Rainha Dona Leonor) na qual, confesso, nunca tinha entrado antes. Em parte fizeram-me escolher a licenciatura que frequentaria nos seguintes 5 anos.

\section{Livro segundo:}

"Lehninger - Principles of

Biochemistry" de Albert L. Lehninger, 1982, Worth Publishers, Inc.

Já na faculdade, esta foi provavelmente a melhor referência de estudo que me foi aconselhada. Sim, fala de bioquímica como o título indica. Mas não nos enganemos pois bioquímica é química. $\mathrm{Na}$ verdade são várias químicas - orgânica, inorgânica, química-física - conjugadas num único vaso reaccional. Apesar de neste momento desactualizado (hoje, obviamente, não o aconselho a qualquer aluno de bioquímica), ao tempo da sua edição era uma obra fundamental para quem quisesse dar os primeiros passos na química da vida. Um milhar de página concisas que falavam de biologia molecular e celular e química biológica. Um livro que serviria a várias cadeiras.

\section{Livro terceiro:}

"Principles of Bioinorganic Chemistry" de Stephen J. Lippard e Jeremy M. Berg, 1994, University Science Books.

Possivelmente já desactualizado, mas ainda um dos melhores livros de publicidade à área de investigação onde realizei doutoramento. Publicado no meu último ano de estudante de doutoramento este livro deu-me a certeza de ter escolhido o caminho correcto. Ainda hoje investigo sobre temas lá contidos. Ainda hoje 0 aconselho a alunos que se iniciam no campo da bioinorgânica e bioquímica-física de proteínas.

Outros livros poderiam constar desta lista, mas o risco de a tornar muito extensa seria demasiado. Que livros estaria eu a descrever neste ex-libris daqui a seis meses? Na verdade não sei. Só sei que marcarão a evolução da investigação que faço e o meu percurso académico. Mas isso apenas advém da verdadeira essência da ciência. 


\section{Un livro teónico para as aulas práilicas}

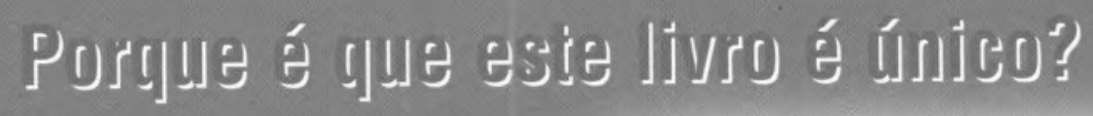

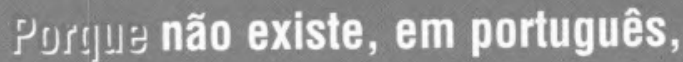
mais nenhuma obra que trate das regras gerais de "comportamento" num laboratório

Por!̣ule chama a atenção para o problema da segurança nos laboratórios

Porg] Ue aborda um conjunto de tópicos essenciais que, por falta de tempo, raramente são tratados nas aulas com um nivel adequado: - Elaboração de relatórios

- Pesquisa bibliográfica

- Aquisição automática de dados

- Análise e tratamento de dados experimentais

- Apresentação de dados em gráficos e medida de algumas propriedades

\section{GUIA DO LABORATÓRIO DE QUÍMICA E BIOQUÍMICA}

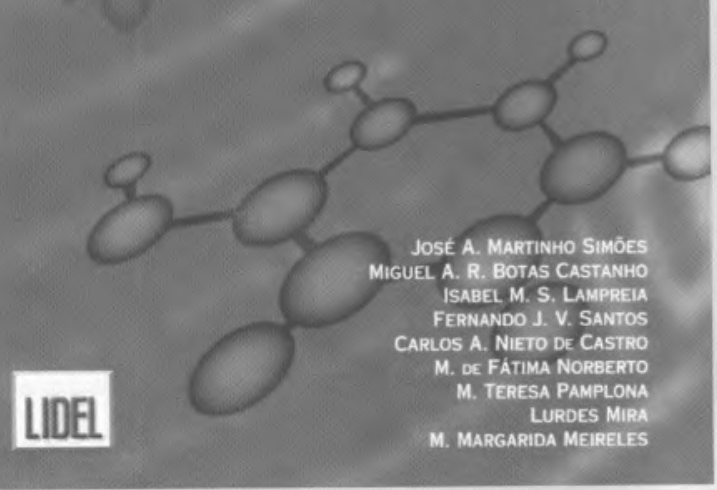

P.V.P.: 2 200\$

D: Direitos te Autor desia obra revertem a favor da Sorjedade Portuguesa de Cuńfrnjea
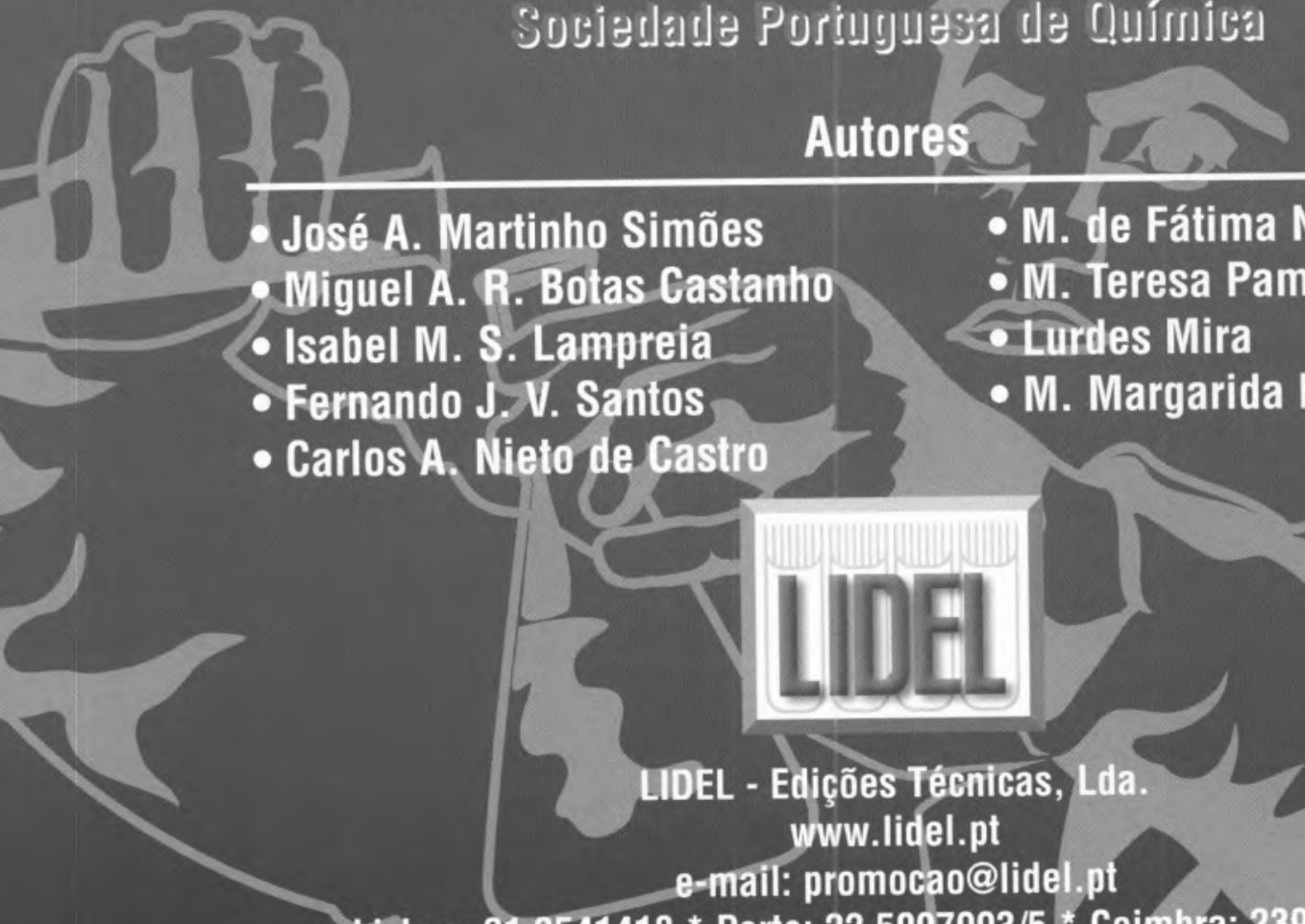

José A. Martinho Simões $\quad$ M. de Fátima Norberto

Miguel A. R. Botas Castanho

- M. Teresa Pamplona

- Isabel M. S. Lampreia -Lurdes Mira

- Fernando J.V. Santos

- M. Margarida Meireles 